OPEN ACCESS

Edited by:

Katsuhiko Suzuki,

Waseda University, Japan

Reviewed by:

Yusuke Hara,

National Institute of Advanced Industrial Science and Technology

(AIST), Japan

Hamid Arazi,

University of Guilan, Iran

*Correspondence:

Guodong Zhang

lygd777@swu.edu.cn

Yang Cao

yang.cao@oru.se

tThese authors have contributed equally to this work and share first authorship

Specialty section:

This article was submitted to

Exercise Physiology,

a section of the journal

Frontiers in Physiology

Received: 08 January 2021

Accepted: 11 February 2021

Published: 12 March 2021

Citation:

Zhang X, Li H, Bi S, Luo Y, Cao Y and

Zhang G (2021) Auto-Regulation

Method vs. Fixed-Loading Method in

Maximum Strength Training for

Athletes: A Systematic Review and

Meta-Analysis.

Front. Physiol. 12:651112

doi: 10.3389/fphys.2021.651112

\section{Auto-Regulation Method vs. Fixed-Loading Method in Maximum Strength Training for Athletes: A Systematic Review and Meta-Analysis}

\author{
Xing Zhang ${ }^{1 \dagger}$, Hansen $\mathrm{Li}^{2 \dagger}$, Shilin $\mathrm{Bi}^{3}$, Yong $\mathrm{Luo}^{1}$, Yang $\mathrm{CaO}^{4,5^{*}}$ and Guodong Zhang ${ }^{2 \star}$ \\ ${ }^{1}$ Department of Basketball and Volleyball, Chengdu Sport University, Chengdu, China, ${ }^{2}$ Key Lab of Physical Fitness \\ Evaluation and Motor Function Monitoring of General Administration of Sports of China, College of Physical Education, \\ Institute of Sports Science, Southwest University, Chongqing, China, ${ }^{3}$ National Institute of Education, Nanyang Technological \\ University, Singapore, Singapore, ${ }^{4}$ Clinical Epidemiology and Biostatistics, School of Medical Sciences, Örebro University, \\ Örebro, Sweden, ${ }^{5}$ Unit of Integrative Epidemiology, Institute of Environmental Medicine, Karolinska Institutet, Stockholm, \\ Sweden
}

The auto-regulation method is a rising training strategy to improve strength and motor performance, and the Autoregulatory Progressive Resistance Exercise (APRE), Rating of Perceived Exertion program (RPE), and Velocity-Based Training (VBT) are the three common auto-regulation programs. However, whether the auto-regulation method is more effective than the traditional strength training (the fixed-loading method) in maximum strength training is still unclear. The present study searched the Pubmed, SPORTDiscus, Web of Science, Embase, EBSCO, Cochrane, CNKI, and CQVIP databases, and included eight related studies published between 2010 and 2020, with a total of 166 subjects including division 1 college players and athletes with at least 1 -year training history, and interventions ranging from 5 to 10 weeks. A meta-analysis was performed to check the difference between the two training methods, and analyzed the differences in the existing auto-regulation programs' effectiveness. The overall results showed that the auto-regulation method was more effective than the fixed-loading method in maximum strength training (effect size $=0.64 ; P<0.001 ; I^{2}=0 \%$ ). In specific, the pooled results in subgroup analysis indicated that the auto-regulation method may effectively improve the strength performance in squat (effect size $=4.64 ; P<0.05 ; I^{2}$ $=54 \%$ ) and bench press (effect size $=3.21 ; P<0.05 ; I^{2}=62 \%$ ). Greater benefits of the auto-regulation method on strength improvement could be achieved in an 8-week or even shorter training (effect size $=0.87 ; P<0.001 ; R^{2}=0 \%$ ) compared with those of $8-10$ weeks (effect size $=0.32 ; P<0.001 ; I^{2}=0 \%$ ). The APRE is the most effective training program among the three auto-regulation programs (effect size $=0.78$; $\left.P<0.001 ; I^{2}=0 \%\right)$. In conclusion, the auto-regulation method could be more effective than the fixed-loading method in maximum strength training. The APRE is a convenient and effective training program that may be considered a practical training program to replace traditional training in athletes.

Keywords: auto-regulation method, fixed-loading method, maximum strength, training, athlete, meta-analysis 


\section{INTRODUCTION}

The maximum strength is known to play a key role in improving and maintaining sports performance, including increased speed (Ronnestad et al., 2008; Chelly et al., 2009; Comfort et al., 2012; Styles et al., 2016), agility (Spiteri et al., 2013, 2015), and explosive strength (HÄKkukinen et al., 1985; Van Cutsem et al., 1998; Aagaard et al., 2002; Chelly et al., 2009; Andersen et al., 2010), and is even conducive to develop motor skills (Suchomel et al., 2016). Besides, the developed maximum strength has also been associated with effective protection in body structures such as bones, ligaments, and tendons, which can further reduce risk in athletic injury and prolong the athletic career (Fleck and Falkel, 1986; Radin, 1986; Stone, 1988; Lehnhard et al., 1996; Lauersen et al., 2014). Therefore, to effectively develop the maximum strength, many attempts have been made to find out a better training method (Materko et al., 2010; Shalfawi and Kjellstadli, 2018).

In the past decades, traditional strength training seems to be the effective method in improving maximum strength, which refers to various training programs designed based on the individual's strength limitation, usually known as the 1RM (One Repetition Maximum) in strength events. Briefly, the working load of a fixed-loading method, such as the training intensity and volume, is designed and fixed before the training gets started, where the name "fixed-loading" of the traditional strength training comes from. In periodical training, the fixed-loading method needs to be performed with an accurate estimation of the supercompensation to achieve effective progress. Due to numerous successful cases, the fixed-loading method has been considered as the best strategy in strength training for a very long time, and has been applied in different sports and people with a varied athletic ability (Rhea et al., 2002; Sander et al., 2013).

However, though the importance of the fixed-loading method is indisputable, it also has some disadvantages. For instance, due to the diurnal variation of the physiological index, the maximum strength can change up to 10-20\% (Poliquin, 1988), and other factors can also affect the sports performance, such as sleeping conditions, warmup programs, and sports supplements intake (Warren et al., 2009; Amiri-Khorasani and René, 2014; de Salles Painelli et al., 2014; Baxter et al., 2016; Abbott et al., 2020; Patterson et al., 2020), which makes it very hard to choose an appropriate working load according to an athlete's body condition (Kraemer and Fleck, 2007), thus the longterm development of strength is limited. Consequently, the uncertainties in training may result in overtraining or inadequate training, and followed by injury or degeneration in training (Poliquin, 1988).

In response, a flexible and adjustable strength training method, known as the auto-regulation method, was therefore developed to address this problem. This method aims to monitor and evaluate whether the working load is reasonable according to the specific performance of athletes. Besides, by regulating the working load (usually training reps and weights), athletes can receive proper training that in accord with their real-time conditions, and thus obtain optimal progress (Flanagan and
Jovanovic, 2014). At present, the auto-regulation method mainly includes three important programs as follows:

(1) The Autoregulatory Progressive Resistance Exercise (APRE) is a program regulated based on the completed reps (Mann, 2011). The APRE program requires athletes to determine the training intensity (weight) of the first and the second sets in advance, and further adjust the training weight of the fourth set according to the completed reps of the third set. If the third set's completed reps are more than the target reps, the weight will be increased. Otherwise, the weight will be reduced.

(2) The Rating of Perceived Exertion program (RPE) is regulated using various RPE measuring scales (Helms et al., 2016). Among the scales, the Borg CR10 Scale (Shariat et al., 2018) and the OMNI-RES Scale (Robertson et al., 2003) were frequently used in the RPE program. The former scale is evaluated by a 10-point Likert scale, while the latter one uses an 11-point Likert scale. For the two scales, a higher score indicates more difficulty in finishing one rep. For example, the RPE 9 means an arduous attempt but still one more rep can be done, and the RPE10 means extremely hard and another rep is impossible.

(3) The Velocity-Based Training (VBT) is a program regulated based on the movement speed during the training (Flanagan and Jovanovic, 2014). This training program highly relies on the speed detector, and linear position sensors or wearable devices are usually employed in the strength training to monitor athletes' movement and provide feedback to regulate the working load. Besides, different training purposes require various speeds. For example, a speed below $0.5 \mathrm{~m} / \mathrm{s}$ is considered effective to develop maximum strength (Izquierdo et al., 2006; Jidovtseff et al., 2009; Jandačka and Beremlijski, 2011). During the training, if the movement speed exceeds the speed range, the load will be increased; otherwise, the load will be reduced or the training will be terminated.

Nowadays, many studies have demonstrated the advantages of the auto-regulation method over the fixed-loading method. For instance, the auto-regulation method contributes to more significant improvements in strength endurance (Mann et al., 2010), explosive strength (Orange et al., 2019b; Dorrell et al., 2020), and speed (Orange et al., 2019a). However, the difference in maximum strength improvement between the auto-regulation method and the fixed-loading method is still unclear. Though some researchers believe that the auto-regulation method is superior to the fixed-loading method in improving the maximum strength (Mann et al., 2010; Mann, 2011; Graham and Cleather, 2019), some other evidence indicates no significant difference between the two training methods (Fisher, 2016; Helms et al., 2018; Patroklos et al., 2018). Therefore, this systematic review and meta-analysis aimed to:

(1) examine the difference between the two training methods;

(2) reveal their functions in different training events and interventions;

(3) quantify the differences among the APRE, RPE, and VBT programs in maximum strength training by synthesizing evidence from current published studies. 


\section{MATERIALS AND METHODS}

\section{Selection Criteria}

The following PICOS criteria for inclusion and exclusion of studies in the present study were:

- P (population): sportspeople who have strength training history for at least one year;

- I (intervention): using auto-regulation methods as intervention;

- C (comparison): using the fixed-loading method as control;

- O (outcomes): the 1RM was measured in the training events;

- S (study design): study design considered randomizedcontrolled trials (RCTs), cohort studies, and comparative studies that evaluated the effects of the auto-regulation methods in maximum strength training.

Meanwhile, the criteria for exclusion were:

- The study was not aimed to improve the maximum strength;

- The sample size did not meet the requirement of meta-analysis.

\section{Data Sources}

A systematical search was conducted in both English and Chinese databases, including Pubmed, SPORTDiscus, Web of Science (all database), Embase, EBSCO (all database), Cochrance, CNKI (in Chinese), and CQVIP (in Chinese). Besides, to include more potential studies, we also screened the references in the preliminarily identified articles and included the related ones.

\section{Searching Strategy}

Databases were searched from the inception of the databases up to October 8, 2020. The detailed strategy was listed in Table 1, demonstrated in Pubmed searching style, and the other databases were searched using the same strategy.

\section{Literature Screening and Data Extraction}

Literature screening was performed by two authors (XZ and HL) independently. The discrepancies were resolved by discussion, or referred to a third author (SB) for opinions. Data extracted include article title, author name, publication year, study design, participant profile, sample size, interventions, intervention measures, control measures, measurements, and outcomes. The number of study participants and means and standard deviations (SD) of 1RM tested before and after intervention were extracted from the articles and included in the meta-analysis. The SD was calculated using the reported standard error and the sample size if it was not directly available in an article.

\section{Quality Assessment}

The PEDro scale (Physiotherapy Evidence-Based Database) was employed in the present study to assess the methodological quality of the included studies. The PEDro, which contains 11 items, has high reliability and validity according to the previous studies (Maher et al., 2003; de Morton, 2009). The items are scored as Yes (1 point), No (0 point), and Don't know (0 point). The first item (methodological item) will be demonstrated but not included in the total score, while the complete assessment takes into account the scores of 2-11 items, and the overall qualities are assessed as excellent (9-10 points), good (6-8 points), fair (4-5 points), and poor ( $<4$ points) (Maher et al., 2003; PEDro Scale Physiotherapy Evidence Database, 2010). The assessment was independently carried out by two authors (HSL, $\mathrm{ZX}$ ), and disagreements were discussed with the third author (SB) until consensus was reached.

\section{Statistical Analysis}

The software Reviewer manager 5.3 was employed for the synthesis of the data. Heterogeneity was assessed using the standard $I^{2}$ index and the chi-square tests. $I^{2}$ values of 25,50 , and $75 \%$ were interpreted as representing small, moderate, and high levels of heterogeneity (Higgins et al., 2003). The randomeffects model was employed for data synthesis if there was a high heterogeneity or inconsistency $\left(I^{2}>50 \%\right)$, otherwise, the fixed-effects model was performed instead. The standardized mean difference (SMD) was used to present the overall synthesis outcomes due to the different training items, while the mean difference (MD) was used to demonstrate the synthesis outcomes in subgroups. A sensitivity analysis was conducted via the leaveone-out method to identify the source of the heterogeneity and further check the stability and reliability of the results.

\section{RESULTS}

\section{Selection of Studies}

In total, 3,040 studies were found from the searching, 3,018 were excluded due to duplication and screening by title and abstract, and 13 were excluded for inappropriate controls. An identified study with 31 subjects and a 12-week intervention was also excluded for data unavailability. As a result, eight studies (seven English studies and one Chinese study), which resulted in 17 reports, were included after the screening (Figure 1). The studies were published between 2010 and 2020. Three studies used the APRE program (Mann et al., 2010; Mann, 2011; Weber, 2015), two used the RPE program (Helms et al., 2018; Patroklos et al., 2018), and three used the VBT program (Fisher, 2016; Singh, 2016; Zhihui, 2020). The control groups used various fixedloading programs, seven studies used the linear periodization programs (Mann et al., 2010; Mann, 2011; Weber, 2015; Fisher, 2016; Singh, 2016; Helms et al., 2018; Patroklos et al., 2018), one study used the fixed load of 75\% 1RM (Zhihui, 2020). In terms of maximum strength measurement, three studies with 49 subjects used the direct test (attempts and failure) (Helms et al., 2018; Patroklos et al., 2018; Zhihui, 2020), and the rest five studies with 117 subjects evaluated the maximum strength via $1 \mathrm{RM}$ formula. A total of 166 subjects (151 males and 15 females) were included. All the subjects were young experienced athletes (training years $>1$ year), and underwent different intervention durations of 510 weeks. Five reports indicated that the auto-regulation methods were more effective in maximum strength training than the fixedloading method, while no significant difference was reported in the rest of the reports, or no statistical test was performed. We conducted the $t$-test if the data were available, but no statistically significant difference was found at the baseline. The detailed information of the included studies is shown in Table 2. 
TABLE 1 | Searching strategy for the study inclusion.

\begin{tabular}{lll}
\hline Steps & Searching command & Field \\
\hline$\# 1$ & Ratings of perceived exertion OR ratings of exertion OR perceived exertion OR RPE OR repetitions in reserve OR RIR OR \\
& autoregulation OR auto-regulation OR VBT OR Velocity Based OR APRE \\
Power training OR strength building OR strength training OR weight work OR resistance exercise OR work against & Title \\
resistance OR powerlifting OR weight lifting OR muscular strength OR 1RM strength & \#1 AND \# 2 AND
\end{tabular}

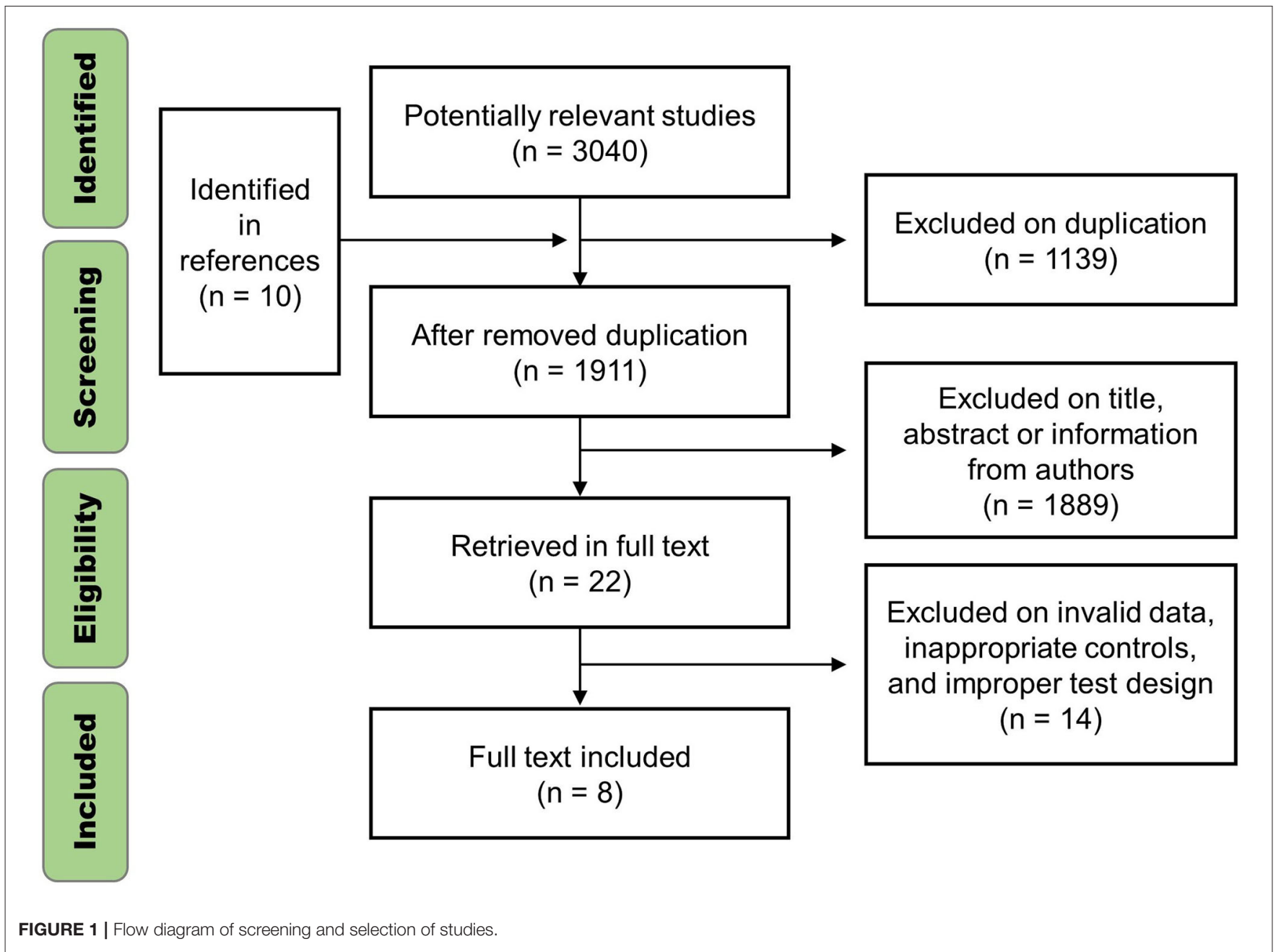

\section{Quality of the Included Studies}

Among the eight included studies, four studies used an RCT design, two used a matched-pairs design, and two used a nonRCT design. Three studies were assessed as good quality, and five as fair quality according to the PEDro scale (Table 3). All the eight studies lacked blinding, including blinding for subjects, therapists, and assessors.

\section{Synthesis of Results}

As no heterogeneity was observed among the 17 included reports $\left(I^{2}=0 \%\right)$, the synthesis was conducted using the fixed-effects model, and pooled results were presented in standard mean difference (SMD). The overall effect size was 0.64 (95\% CI $0.43-$ $0.85 ; P<0.001$ ) (Figure 2).

Squat and bench press are the two main training events in the included studies (the other events were only investigated in one or two studies). Therefore, the subgroup analysis was performed to check the effects of auto-regulation methods on different events. As the 1RM was tested for squat and bench press in the included studies, the pooled results were presented in mean difference $(\mathrm{MD})$, and due to medium to high heterogeneity was observed in the synthesis of both subgroups $\left(I^{2}>50 \%\right)$, the random-effects model was employed, and the overall effects of squat and bench press were $4.65(95 \% \mathrm{CI} 0.56-8.73 ; P<0.05)$ and 3.21 (95\% CI 0.34-6.09; $P<0.05$ ), respectively (Figure 3). No 
TABLE 2 | Characteristics of studies included in the present study.

\begin{tabular}{|c|c|c|c|c|c|c|c|c|c|c|c|c|c|}
\hline \multirow[t]{2}{*}{ Authors } & \multirow{2}{*}{ Interventiol } & \multirow{2}{*}{ Design } & \multirow{2}{*}{$\begin{array}{c}\text { 1RM } \\
\text { measureme }\end{array}$} & \multirow{2}{*}{$\begin{array}{l}\text { Gender } \\
\text { nt }\end{array}$} & \multicolumn{4}{|c|}{ Intervention group } & \multicolumn{4}{|c|}{ Control group } & \multirow{2}{*}{$\begin{array}{l}\text { Results (superior } \\
\text { method) }\end{array}$} \\
\hline & & & & & Subjec & t Training year & Age & Training program & Subjec & t Training year & age & Training program & \\
\hline \multirow[t]{2}{*}{ Mann et al. (2010) } & 6 weeks & Non-RCT & ES & Male & 12 & $2.9 \pm 0.7$ & $20.2 \pm 1.0$ & Bench press (APRE) & 11 & $2.43 \pm 0.7$ & $20.3 \pm 1.6$ & Bench press (Fixed) & Auto \\
\hline & & & & & & & & Squat (APRE) & & & & Squat (Fixed) & $P=0.05$ \\
\hline \multirow[t]{4}{*}{ Weber (2015) } & 8 weeks & $\mathrm{RCT}$ & ES & Male & 9 & $9.9 \pm 3.4$ & $20.4 \pm 1.6$ & Squat (APRE) & 9 & $10.3 \pm 2.6$ & $20.0 \pm 1.1$ & Squat (Fixed) & n. s. \\
\hline & & & & & & & & Bench press (APRE) & & & & Bench press (Fixed) & Auto \\
\hline & & & & & & & & $\begin{array}{l}\text { Right grip strength } \\
\text { (APRE) }\end{array}$ & & & & $\begin{array}{l}\text { Right grip strength } \\
\text { (Fixed) }\end{array}$ & n. s. \\
\hline & & & & & & & & Left grip strength (APRE) & & & & $\begin{array}{l}\text { Left grip strength } \\
\text { (Fixed) }\end{array}$ & n. s. \\
\hline \multirow[t]{3}{*}{ Mann (2011) } & 6 weeks & Non-RCT & ES & Male & 32 & Division 1 college & 19.62 & Bench press (APRE) & 25 & Division 1 college & e 19.13 & Bench press (Fixed) & Auto \\
\hline & & & & & & player & & Squat (APRE) & & player & & Squat (Fixed) & Auto \\
\hline & & & & & & & & Clean (APRE) & & & & Clean (Fixed) & Auto \\
\hline \multirow[t]{2}{*}{ Helms et al. (2018) } & 8 weeks & MPD & DT & Male & 10 & $>2$ & $20.9 \pm 1.4$ & Squat (RPE) & 11 & $>2$ & $23.8 \pm 4.2$ & Squat (Fixed) & n. s. \\
\hline & & & & & & & & Bench press (RPE) & & & & Bench press (Fixed) & n. s. \\
\hline \multirow{3}{*}{$\begin{array}{l}\text { Patroklos et al. } \\
\text { (2018) }\end{array}$} & 10 weeks & MPD & DT & Male & 5 & $>2$ & $27 \pm 6$ & Squat (RPE) & 3 & $>2$ & $27 \pm 6$ & Squat (Fixed) & n. s. \\
\hline & & & & & & & & Bench press (RPE) & & & & Bench press (Fixed) & n. s. \\
\hline & & & & & & & & Deadlift (RPE) & & & & Deadlift (Fixed) & n. s. \\
\hline Zhihui (2020) & 8 weeks & $\mathrm{RCT}$ & DT & Male & 10 & $3.20 \pm 0.42$ & $20.10 \pm 0.88$ & Squat (VBT) & 10 & $3.20 \pm 0.42$ & $20.10 \pm 0.88$ & Squat (fixed) & n. s. \\
\hline Singh (2016) & 5 weeks & $\mathrm{RCT}$ & ES & Male & 2 & $>2$ & $22.2 \pm 1.3$ & Bench press (VBT) & 2 & $>2$ & $22.2 \pm 1.3$ & Bench press (Fixed) & n. s. \\
\hline Fisher (2016) & 6 weeks & $\mathrm{RCT}$ & ES & Female & 8 & $>1$ & $20.00 \pm 0.9$ & Bench press (VBT) & 7 & $>1$ & $20.67 \pm 0.9$ & Bench press (Fixed) & n. s. \\
\hline
\end{tabular}

RCT, randomized controlled trails; MPD, matched-pairs design; Auto, auto-regulation method; n.s., non-significant difference; APRE, Autoregulatory Progressive Resistance Exercise; RPE, Rating of Perceived Exertion program; VBT, Velocity-Based Training; Fixed, fixed-loading programs; DT, direct test for 1RM; ES, 1RM was estimated via formula. 
TABLE 3 | Quality assessment of the included studies.

\begin{tabular}{|c|c|c|c|c|c|c|c|c|c|c|c|c|c|}
\hline \multirow[t]{2}{*}{ Study } & \multicolumn{12}{|c|}{ PEDro item } & \multirow[b]{2}{*}{ Assessment } \\
\hline & 1 & 2 & 3 & 4 & 5 & 6 & 7 & 8 & 9 & 10 & 11 & Total & \\
\hline Mann et al. (2010) & Yes & & & & & & & 1 & 1 & 1 & 1 & 4 & Fair \\
\hline Weber (2015) & No & 1 & & 1 & & & & 1 & 1 & 1 & 1 & 6 & Good \\
\hline Mann (2011) & No & & & 1 & & & & 1 & 1 & 1 & 1 & 5 & Fair \\
\hline Helms et al. (2018) & Yes & & & 1 & & & & 1 & 1 & 1 & 1 & 5 & Fair \\
\hline Patroklos et al. (2018) & Yes & & & 1 & & & & & 1 & 1 & 1 & 4 & Fair \\
\hline Zhihui (2020) & Yes & 1 & & 1 & & & & 1 & 1 & 1 & 1 & 6 & Good \\
\hline Singh (2016) & Yes & 1 & & 1 & & & & & 1 & 1 & 1 & 5 & Fair \\
\hline Fisher (2016) & Yes & 1 & & 1 & & & & 1 & 1 & 1 & 1 & 6 & Good \\
\hline
\end{tabular}

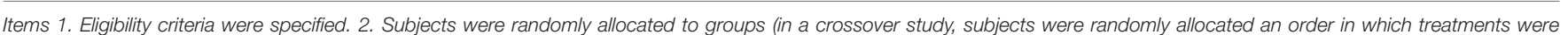

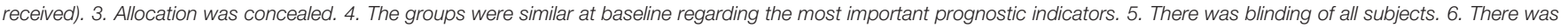

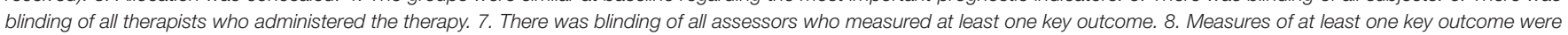

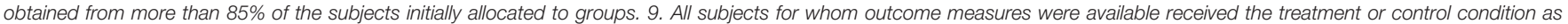

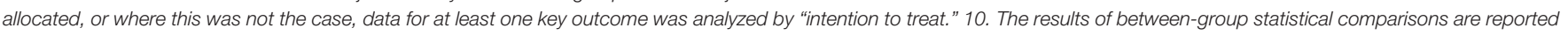
for at least one key outcome. 11. The study provides both point measures and measures of variability for at least one key outcome.

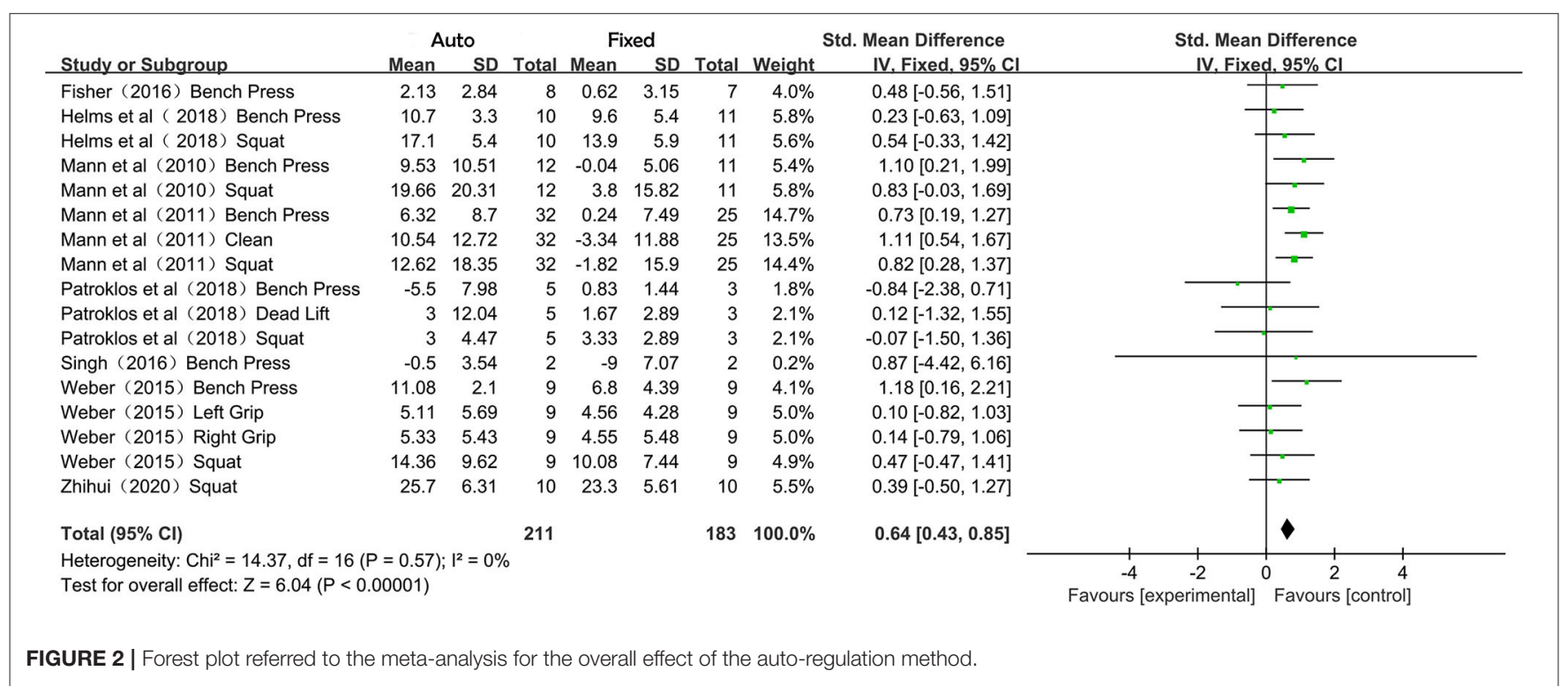

statistically significant difference was found in the overall effects between the two training events $(P=0.57)$.

Due to the varied duration of intervention, the included studies were divided into short-term intervention ( $<8$ weeks) and medium-term intervention ( $\geq 8$ weeks). The subgroup analysis was carried out and the pooled results were presented in SMD (Figure 4). As no heterogeneity was observed in each of the subgroup synthesis $\left(I^{2}=0 \%\right)$, the fixed-effects model was employed, and the overall effects of the short-term and longterm intervention were 0.32 (95\% CI $0.00-0.64 ; P=0.05)$ and 0.87 (95\% CI $0.60-1.14 ; P<0.001$ ). A statistically significant difference was found in the overall effects between the subgroups $(P=0.01)$.

Due to the different events in the training programs, the subgroup analysis was performed and presented in SMD to compare the difference between APRE, RPE, and VBT training programs (Figure 5). As no heterogeneity was observed in each of the subgroup synthesis $\left(I^{2}=0 \%\right)$, the fixed-effects model was therefore employed, and the overall effects of APRE, RPE, and VBT were 0.78 (95\% CI 0.54-1.02; $P<0.05), 0.17$ (95\% CI $-0.33-0.67 ; P=0.50)$, and 0.43 (95\% CI $-0.24-1.10 ; P=0.21$ ), respectively. No statistically significant difference was found in overall effects between the three methods $(P=0.08)$.

\section{Sensitivity Analysis}

Due to the varied retrieved data, both the fixed- and randomeffects models were used in the present study. To check the reliability of the results, we switched the used models for each of the synthesis, and the significance of the differences remained in each of the comparisons. As heterogeneity was observed in the squat and bench press data, the leave-one-out method was used to identify the source of the heterogeneity. The results indicated that two studies (Mann et al., 2010; Patroklos et al., 2018) were responsible for the high heterogeneity in 


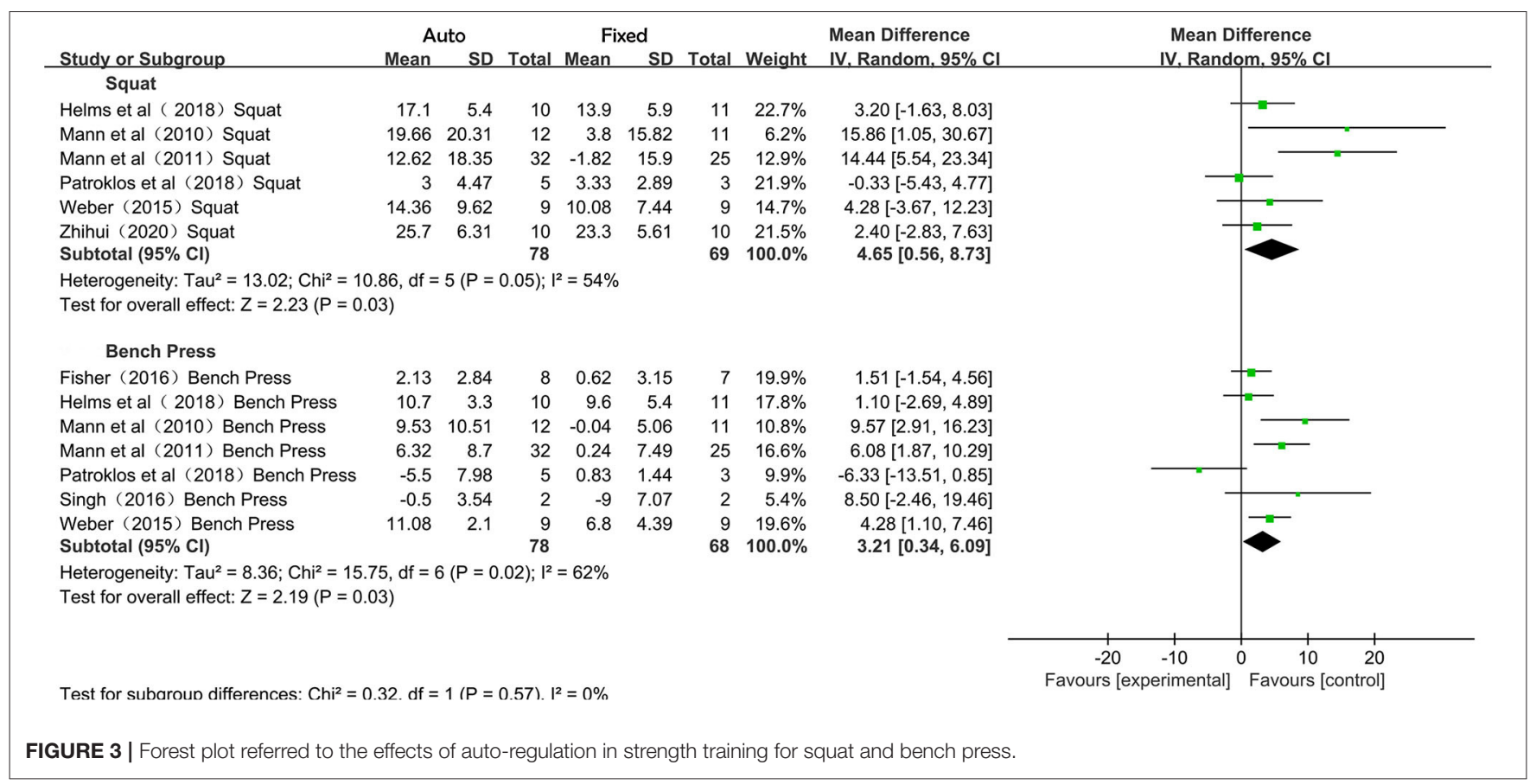

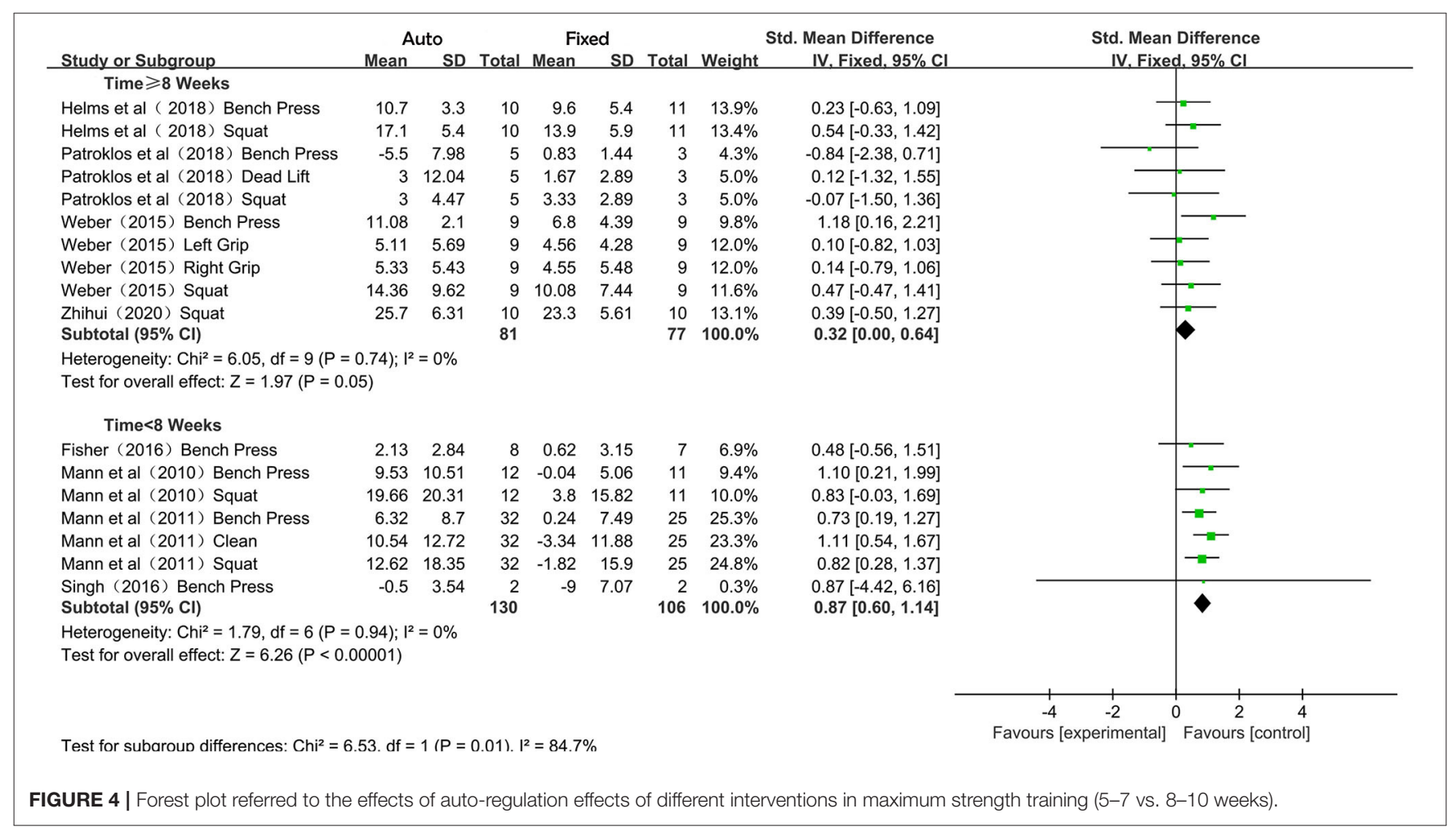

the bench press subgroup, and the $I^{2}$ decreased from 62 to $27 \%$ after removing the two studies, and the difference was still statistically significant $(\mathrm{MD}=3.27,95 \%$ CI $1.18-5.37$, $P<0.05)$. Likewise, after removing the two studies (Mann, 2011; Patroklos et al., 2018), heterogeneity was eliminated $\left(I^{2}=0 \%\right)$, and the difference remained significant when the fixed-effects model was employed (MD = 3.66, 95\% CI 0.49-6.82, $P<0.05)$.

\section{Publication Bias}

The funnel plot demonstrated more studies were distributed toward the left at the top of the graph, indicating a potential risk 


\begin{tabular}{|c|c|c|c|c|c|c|c|c|c|c|}
\hline & \multicolumn{3}{|c|}{ Auto } & \multicolumn{2}{|c|}{ Fixed } & & & \multirow{2}{*}{$\begin{array}{l}\text { Std. Mean Difference } \\
\text { IV. Fixed, } 95 \% \mathrm{Cl}\end{array}$} & \multirow{2}{*}{\multicolumn{2}{|c|}{$\begin{array}{l}\text { Std. Mean Difference } \\
\text { IV. Fixed, } 95 \% \mathrm{Cl}\end{array}$}} \\
\hline & Mean & SD & Total & Mean & SD & Total & Weight & & & \\
\hline \multicolumn{11}{|l|}{ APRE } \\
\hline Mann et al (2010) Bench Press & 9.53 & 10.51 & 12 & -0.04 & 5.06 & 11 & $7.5 \%$ & $1.10[0.21,1.99]$ & & - \\
\hline Mann et al (2010) Squat & 19.66 & 20.31 & 12 & 3.8 & 15.82 & 11 & $8.0 \%$ & $0.83[-0.03,1.69]$ & & \\
\hline Mann et al (2011) Bench Press & 6.32 & 8.7 & 32 & 0.24 & 7.49 & 25 & $20.1 \%$ & $0.73[0.19,1.27]$ & & $\rightarrow$ \\
\hline Mann et al (2011) Clean & 10.54 & 12.72 & 32 & -3.34 & 11.88 & 25 & $18.5 \%$ & $1.11[0.54,1.67]$ & & 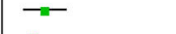 \\
\hline Mann et al (2011) Squat & 12.62 & 18.35 & 32 & -1.82 & 15.9 & 25 & $19.8 \%$ & $0.82[0.28,1.37]$ & & $-\infty$ \\
\hline Weber (2015) Bench Press & 11.08 & 2.1 & 9 & 6.8 & 4.39 & 9 & $5.6 \%$ & $1.18[0.16,2.21]$ & & \\
\hline Weber (2015) Left Grip & 5.11 & 5.69 & 9 & 4.56 & 4.28 & 9 & $6.9 \%$ & $0.10[-0.82,1.03]$ & & 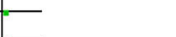 \\
\hline Weber (2015) Right Grip & 5.33 & 5.43 & 9 & 4.55 & 5.48 & 9 & $6.9 \%$ & $0.14[-0.79,1.06]$ & & \\
\hline Weber (2015) Squat & 14.36 & 9.62 & 9 & 10.08 & 7.44 & 9 & $6.7 \%$ & $0.47[-0.47,1.41]$ & & \\
\hline Subtotal $(95 \% \mathrm{Cl})$ & & & 156 & & & 133 & $100.0 \%$ & $0.78[0.54,1.02]$ & & $\bullet$ \\
\hline \multicolumn{11}{|c|}{$\begin{array}{l}\text { Heterogeneity: } \mathrm{Chi}^{2}=6.79, \mathrm{df}=8(\mathrm{P}=0.56) ; \mathbf{l}^{2}=0 \% \\
\text { Test for overall effect: } Z=6.29(P<0.00001)\end{array}$} \\
\hline \multicolumn{11}{|l|}{ RPE } \\
\hline Helms et al (2018) Bench Press & 10.7 & 3.3 & 10 & 9.6 & 5.4 & 11 & $33.4 \%$ & $0.23[-0.63,1.09]$ & & \\
\hline Helms et al ( 2018) Squat & 17.1 & 5.4 & 10 & 13.9 & 5.9 & 11 & $32.2 \%$ & $0.54[-0.33,1.42]$ & & \\
\hline Patroklos et al (2018) Bench Press & -5.5 & 7.98 & 5 & 0.83 & 1.44 & 3 & $10.4 \%$ & $-0.84[-2.38,0.71]$ & & \\
\hline Patroklos et al (2018) Dead Lift & 3 & 12.04 & 5 & 1.67 & 2.89 & 3 & $12.0 \%$ & $0.12[-1.32,1.55]$ & & \\
\hline Patroklos et al (2018) Squat & 3 & 4.47 & 5 & 3.33 & 2.89 & 3 & $12.0 \%$ & $-0.07[-1.50,1.36]$ & & \\
\hline Subtotal $(95 \% \mathrm{Cl})$ & & & 35 & & & 31 & $100.0 \%$ & $0.17[-0.33,0.67]$ & & \\
\hline \multicolumn{11}{|c|}{$\begin{array}{l}\text { Heterogeneity: } \text { Chi }^{2}=2.47, d f=4(P=0.65) ; l^{2}=0 \% \\
\text { Test for overall effect: } Z=0.67(P=0.50)\end{array}$} \\
\hline \multicolumn{11}{|l|}{ VBT } \\
\hline Fisher (2016) Bench Press & 2.13 & 2.84 & 8 & 0.62 & 3.15 & 7 & $41.7 \%$ & $0.48[-0.56,1.51]$ & & - \\
\hline Singh (2016) Bench Press & -0.5 & 3.54 & 2 & -9 & 7.07 & 2 & $1.6 \%$ & $0.87[-4.42,6.16]$ & & \\
\hline Zhihui (2020) Squat & 25.7 & 6.31 & 10 & 23.3 & 5.61 & 10 & $56.7 \%$ & $0.39[-0.50,1.27]$ & & \\
\hline Subtotal $(95 \% \mathrm{Cl})$ & & & 20 & & & 19 & $100.0 \%$ & $0.43[-0.24,1.10]$ & & \\
\hline \multicolumn{11}{|c|}{$\begin{array}{l}\text { Heterogeneity: } \mathrm{Chi}^{2}=0.04, \mathrm{df}=2(\mathrm{P}=0.98) ; \mathrm{I}^{2}=0 \% \\
\text { Test for overall effect: } Z=1.26(\mathrm{P}=0.21)\end{array}$} \\
\hline Test for subaroun differences: $\mathrm{Ch}^{2}=$ & & $=2(P=->>2$ & 08) $\left.\right|^{2}+2-5$ & $2=6055^{\circ}+2-50$ & & & & & $\begin{array}{ccc}-4 & -2 & 0 \\
\text { Favours [experimental] }\end{array}$ & $\begin{array}{lll}0 & 2 & 4 \\
\text { Favours [control] }\end{array}$ \\
\hline
\end{tabular}

of bias (Figure 6). However, the plot was still close to symmetric, suggesting weak evidence of publication bias.

\section{DISCUSSION}

The present study aimed to compare the effects of autoregulation and fixed-loading methods in maximum strength training, and checking the difference between different autoregulation programs was another goal. As far as we know, our study was the first attempt to make such a comparison. The overall results indicated that the auto-regulation method was more effective in improving maximum strength than the fixed-loading method. As we stated in the Introduction section, considerable disagreements have remained in the previous studies (Mann et al., 2010; Mann, 2011; Fisher, 2016; Helms et al., 2018; Graham and Cleather, 2019; Peta, 2019; Dorrell et al., 2020). Based on the included studies, those controversial results might partly result from the different sample sizes. As the interventions disturbed the original training arrangement, these interventions may cause negative impacts on competitive results, especially for professional athletes, making it hard to recruit experienced athletes or conduct long-term interventions. Therefore, limited subjects were included in these studies, thus may lead to subtle differences. In the present study, the most significant results were reported in the study by Mann (2011), which had the largest sample size (57 athletes) among the included studies. In contrast, those with eight or fewer subjects only reported negative results (Fisher, 2016; Singh, 2016; Patroklos et al., 2018). In response, our meta-analysis included 166 experienced athletes from the studies with good or fair qualities, and provided strong evidence of using the auto-regulation method to enhance maximum strength in athletes.

Because the events, duration, and frequency of training were controlled in the treatment and control groups, the advantages of auto-regulation that we observed could be attributed to the different working loads, including various training intensities and volumes. In fact, some included studies and other related studies have reported that auto-regulation programs produced different working loads compared to the fixed-loading counterparts (Singh, 2016; Styles et al., 2016; Helms et al., 2018; Graham and Cleather, 2019; Dorrell et al., 2020). Theoretically, skeletal muscle growth and strength performance are regulated by neurogenic and myogenic factors (Rubinstein and Kelly, 1978; Kelly and Rubinstein, 1980), which are closely associated with the working load in training. Specifically, the different working loads can result in differential neuromuscular system adaption and growth hormone secretion, further affecting the performance and development of muscular strength. In general, our findings supported the theory in previous studies that the auto-regulation methods may provide more suitable working loads to maximize the training benefits (Eston et al., 1987; Naclerio et al., 2011; Scott et al., 2013; Dorrell, 2019), and also reduce risks in muscle 


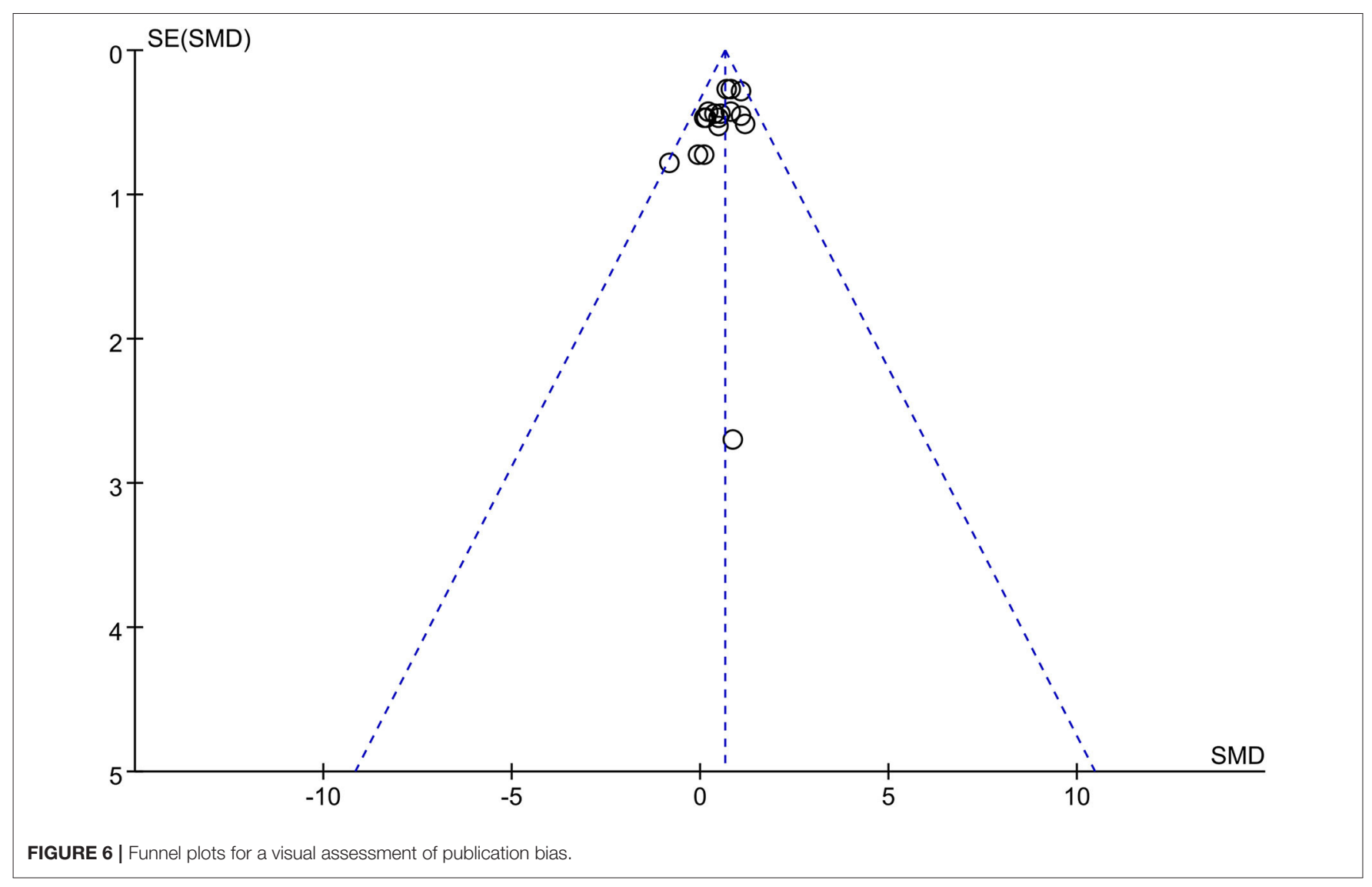

damage and tissue injury that may result from exhaustive exercise (Suzuki et al., 2020).

Bench press and squat are the main training events in the included studies for quantitative synthesis, and the pooled results demonstrated that the auto-regulation methods increased the maximum strength for both training events. In the published literature, the bench press and squat are the core tests for athletes' fundamental strength, and play essential roles in athletic performances (Hoffman et al., 2007; Patrick et al., 2011), thus these results indicated the significance of the auto-regulation method in enhancing fundamental strength. In addition, competing athletes usually need integrated training to improve athletic performance, such as plyometrics training combined with strength training (Cherni et al., 2021). The autoregulation method may provide flexible training arrangements for athletes to finish their training goals. For instance, there is evidence showing that athletes who resorted to the autoregulation method for strength training had better performances in athletic performances, such as increased levels of agility and vertical jump (Styles et al., 2016; Arede et al., 2020; Zhihui, 2020). Considering that the included subjects were majored in various sports, including basketball (Dorrell et al., 2020), wrestling (Weber, 2015), and football (Mann et al., 2010; Mann, 2011), our findings further suggested the potential of the auto-regulation method in improving athletic performance for various sports.
In the previous studies on physical interventions, we found that a large number of training programs used 5-7 weeks to obtain significant results (Tesch et al., 2004; Ghigiarelli et al., 2009; McLeod et al., 2009; Genevois et al., 2014; Luebbers et al., 2014; Yan et al., 2016). Therefore, we divided the included studies into two groups, one with interventions of 5-7 weeks, and the other of 8-10 weeks. We found that the auto-regulation programs with shorter interventions (5-7 weeks) induced a significantly greater improvement than the fixed-loading counterparts. By comparison, those with longer interventions (8-10 weeks) induced a subtle difference $(P=$ 0.05). Moreover, a significant difference was found between the two groups, indicating that the auto-regulation method might only contribute to short-term advantages. However, these results need to be further confirmed, because the longer interventions only ranged from 8 to 10 weeks due to the study design, and some other studies with longer interventions, such as an identified study of a 12-week intervention, were not included because of the invalid data (Graham and Cleather, 2019). Besides, fewer subjects participated in the longer interventions (81 vs. 130 subjects), which may affect the significance of the results. As we stated before, professional athletes may not participate in a time-consuming intervention, and also many subjects failed to complete the interventions (Helms et al., 2018; Patroklos et al., 2018), thus leading to limited results. 
Among the AREP, RPR, and VBT programs, we found the APRE program more effective in improving the maximum strength compared to the fixed-loading method. However, a non-significant difference was found in the results of RPE and VBT programs. The reason for the differential results was still unknown, which might be associated with used measuring scales and the required equipment. The APRE program is regulated based on the completion reps, which does not require equipment and specific knowledge or experience, and therefore is easily accepted and well-applied. In contrast, the RPE program needs subjects to estimate their exertion precisely, which may cause difficulties in interventions. Some studies have reported that many subjects cannot estimate their exertion properly according to the measuring scale (Hackett et al., 2017; Steele et al., 2017; Keller et al., 2018), which may lead to some improper training (intensity and volume) during the intervention, and could be a potential reason for the non-significant difference. In the case of the VBT program, though the training is regulated based on the velocity that is unlikely limited by subjects' knowledge, the higher requirements in equipment and complex operations may cause inconvenience in training (Gomez-Piriz et al., 2013; Kimitake et al., 2015; Banyard et al., 2017; Orange et al., 2019a), which may further exert negative impacts on subjects' efforts in multiple interventions, and even mask the effects of autoregulation. Moreover, in the present study, 53 subjects were involved in the APRE program, while only 15 and 20 subjects were involved in the RPE and VBT programs, respectively, and only the VBT program included female subjects, which may also partially explain the non-significant results.

On the other hand, though the RPE and VBT programs seemed no better than the fix-loading counterparts, they still showed potential in maximum strength training (Fisher, 2016; Helms et al., 2018; Patroklos et al., 2018; Zhihui, 2020). For instance, among those studies showing non-significant comparisons, Zhihui (2020) reported that both the VBT and fixed-loading programs induced improvements in maximum strength, and the increase obtained in the VBT program was statistically significant. Similarly, Helms et al. (2018) also reported that the maximum strength of subjects increased significantly from the baseline due to the RPE program. Taken together, these results indicated the effectiveness of the VBT and RPE programs in strength training.

With the intriguing findings in the present study, there are still some limitations. Overall, the auto-regulation method is a rising training method and widely commended, but its function in maximum strength training has not received sufficient concerns, which might be due to the difficulties in recruiting subjects and conducting long-term interventions. Therefore, only a few studies met the inclusion criteria of the present study, and our findings in subgroup analysis still need further validation. Besides, the present study only included experienced athletes, but whether the auto-regulation methods are suitable for sportspeople at different athletics levels is still unknown. Furthermore, to reduce the risk of injury in failed 1RM attempts and avoid invalid results due to inappropriate lifting strategies, many studies choose to evaluate the maximum strength via the
1RM formula (Niewiadomski et al., 2008; Grgic et al., 2020). However, the accuracy of evaluation can be affected by formula types, training items, completed reps, and subjects' characteristics (Wentworth and Abadie, 1998; Julio et al., 2012; DiStasio, 2014). In the included studies, only 49 (29.5\%) subjects used the direct test, and they underwent different training programs and durations, making it hard to compare the differences between the two 1RM measurements. Nevertheless, the 1RM formula is still accepted as an effective and practical tool for maximum strength evaluation (Grgic et al., 2020), and future reviews may need to focus on the studies using the same formula and similar subjects to give more accurate results. In addition, only one included study recruited 15 female subjects, and they only participated in the VBT program, thus, we only evaluated the effects based on all subjects, and the gender difference was not analyzed, which may remain a future topic. Finally, the bench press and squat are the two training events involved in most studies, while other classical training, such as the deadlift and clean and jerk, was investigated only in one study (Patroklos et al., 2018); therefore, their effects are still inconclusive and remain to be investigated.

\section{CONCLUSIONS}

The present systematical review and meta-analysis aimed to compare the differences in maximum strength improvement between the auto-regulation methods and fixed-loading methods. Our findings suggest that the auto-regulation method is more effective in improving maximum strength, which may help to improve the squat and bench press strength and further improve athletic performance, and athletes may largely benefit from the auto-regulation method by training of 5-7 weeks. Among the APRE, PRE, and VBT programs, the APRE may be the best option in the auto-regulation method, which is more effective and requires no equipment or training knowledge, thus may be of better potential in athlete training. Due to the limited available data, further investigation is warranted to better understand the advantages of different auto-regulation programs and figure out how maximum strength responds to various intervention duration interventions. Moreover, studies are needed to focus on female athletes and sportspeople at various athletics levels.

\section{DATA AVAILABILITY STATEMENT}

The original contributions presented in the study are included in the article/supplementary material, further inquiries can be directed to the corresponding authors.

\section{AUTHOR CONTRIBUTIONS}

$\mathrm{XZ}$ and HL wrote the manuscript, and SB joined in the discussion for paper inclusion and helped with the English editing. YL reviewed and helped revise the manuscript. YC and GZ supervised the project and amended the final version of the manuscript. All authors contributed to the article and approved the submitted version. 


\section{REFERENCES}

Aagaard, P., Simonsen, E. B., Andersen, J. L., Magnusson, P., and Dyhre-Poulsen, P. (2002). Increased rate of force development and neural drive of human skeletal muscle following resistance training. J. Appl. Physiol. 93, 1318-1326. doi: 10.1152/japplphysiol.00283.2002

Abbott, W., Brett, A., Watson, A. W., Brooker, H., and Clifford, T, (2020). Sleep restriction in elite soccer players: effects on explosive power, wellbeing, and cognitive function. Res. Q. Exerc. Sport 1-8. doi: 10.1080/02701367.2020.1834071 Available online at: https://repository. lboro.ac.uk/articles/journal_contribution/Sleep_restriction_in_elite_soccer_ players_Effects_on_explosive_power_wellbeing_and_cognitive_function/ 13123046

Amiri-Khorasani, M., and René, E. D. F. (2014). The acute effect of stretching on the kinematics of instep kicking in soccer. Sports Technol. 7, 69-78. doi: 10.1080/19346182.2014.893348

Andersen, L. L., Andersen, J. L., Zebis, M. K., and Aagaard, P. (2010). Early and late rate of force development: differential adaptive responses to resistance training? Scand. J. Med. Sci. Sports 20, e162-e169. doi: 10.1111/j.1600-0838.2009.00933.x

Arede, J., Vaz, R., Gonzalo-Skok, O., Carlos, B.-F., and Leite, N. (2020). Repetitions in reserve vs. maximum effort resistance training programs in youth female athletes. J. Sports Med. Phys. Fitness 60, 1231-1239. doi: $10.23736 / S 0022-4707.20 .10907-1$

Banyard, H. G., Nosaka, K., Sato, K., and Haff, G. G. (2017). Validity of various methods for determining velocity, force, and power in the back squat. Int. J. Sports Physiol. Perform. 12, 1170-1176. doi: 10.1123/ijspp.2016-0627

Baxter, C., Naughton, L. R. M., Sparks, A., Norton, L., and Bentley, D. (2016). Impact of stretching on the performance and injury risk of longdistance runners. Res. Sports Med. 25, 78-90. doi: 10.1080/15438627.2016.12 58640

Chelly, M. S., Fathloun, M., Cherif, N., Amar, M. B., Tabka, Z., and Van Praagh, E. (2009). Effects of a back squat training program on leg power, jump, and sprint performances in junior soccer players. J. Strength Cond. Res. 23, 2241-2249. doi: 10.1519/JSC.0b013e3181b86c40

Cherni, Y., Hammami, M., Jelid, M., Aloui, G., Suzuki, K., Shephard, R., et al. (2021). Neuromuscular adaptations and enhancement of physical performance in female basketball players after 8 weeks of plyometric training. Front. Physiol. 11:588787. doi: 10.3389/fphys.2020.588787

Comfort, P., Haigh, A., and Matthews, M. J. (2012). Are changes in maximal squat strength during preseason training reflected in changes in sprint performance in rugby league players? J. Strength Cond. Res. 26, 772-776. doi: 10.1519/JSC.0b013e31822a5cbf

de Morton, N. A. (2009). The PEDro scale is a valid measure of the methodological quality of clinical trials: a demographic study. Aust. J. Physiother. 55, 129-133. doi: 10.1016/S0004-9514(09)70043-1

de Salles Painelli, V., Alves, V. T., Ugrinowitsch, C., Benatti, F. B., Artioli, G. G., Lancha, A. H., et al. (2014). Creatine supplementation prevents acute strength loss induced by concurrent exercise. Eur. J. Appl. Physiol. 114, 1749-1755. doi: 10.1007/s00421-014-2903-0

DiStasio, T. J. (ed.). (2014). Validation of the Brzycki and Epley Equations for the 1 Repetition Maximum Back Squat Test in Division I College Football Players. Carbondale, IL. Southern Illinois University.

Dorrell, H. F. (2019). The Application of the Load-Velocity Relationship as a Means of Dictating Resistance Training Intensity. Lincoln: University of Lincoln.

Dorrell, H. F., Smith, M. F., and Gee, T. I. (2020). Comparison of velocitybased and traditional percentage-based loading methods on maximal strength and power adaptations. J. Strength Cond. Res. 34, 46-53. doi: 10.1519/JSC.0000000000003089

Eston, R., Davies, B., and Williams, J. (1987). Use of perceived effort ratings to control exercise intensity in young healthy adults. Eur. J. Appl. Physiol. Occup. Physiol. 56, 222-224. doi: 10.1007/BF00640648

Fisher, D. L. (2016). Velocity-Based Training as a Method of Auto-Regulation in Collegiate Athletes. Bellingham, WA: WWU Graduate School Collection.

Flanagan, E., and Jovanovic, M. (2014). Researched applications of velocity based strength training. J. Aust. Strength Cond 22, 58-69. Available online at: https:// www.strengthandconditioning.org/jasc-22-2

Fleck, S. J., and Falkel, J. E. (1986). Value of resistance training for the reduction of sports injuries. Sports Med. 3, 61-68. doi: 10.2165/00007256-198603010-00006
Genevois, C., Berthier, P., Guidou, V., Muller, F., Thiebault, B., and Rogowski, I. (2014). Effects of 6-week sling-based training of the external-rotator muscles on the shoulder profile in elite female high school handball players. J. Sport Rehabil. 23, 286-295. doi: 10.1123/JSR.2012-0108

Ghigiarelli, J. J., Nagle, E. F., Gross, F. L., Robertson, R. J., Irrgang, J. J., and Myslinski, T. (2009). The effects of a 7-week heavy elastic band and weight chain program on upper-body strength and upper-body power in a sample of division 1-AA football players. J Strength Cond. Res. 23, 756-764. doi: 10.1519/JSC.0b013e3181a2b8a2

Gomez-Piriz, P. T., Sanchez, E. T., Manrique, D. C., and Gonzalez, E. P. (2013). Reliability and comparability of the accelerometer and the linear position measuring device in resistance training. J. Strength Cond. Res. 27, 1664-1670. doi: 10.1519/JSC.0b013e318269f809

Graham, T., and Cleather, D. J. (2019). Autoregulation by "repetitions in reserve" leads to greater improvements in strength over a 12week training program than fixed loading. J. Strength Cond. Res. 1-7. doi: 10.1519/JSC.0000000000003164 [Epub ahead of print]. Available online at: https://journals.lww.com/nsca-jscr/Abstract/9000/Autoregulation_by_ Repetitions_in_Reserve_Leads.94836.aspx

Grgic, J., Lazinica, B., Schoenfeld, B. J., and Pedisic, Z. (2020). test-retest reliability of the one-repetition maximum (1RM) strength assessment: a systematic review. Sports Med. Open 6, 1-16. doi: 10.1186/s40798-020-00260-z

Hackett, D. A., Cobley, S. P., Davies, T. B., Michael, S. W., and Halaki, M. (2017). accuracy in estimating repetitions to failure during resistance exercise. J. Strength Cond. Res. 31, 2162-2168. doi: 10.1519/JSC.0000000000001683

HÄKkukinen, K., Komi, P. V., and Alén, M. (1985). Effect of explosive type strength training on isometric force- and relaxation-time, electromyographic, and muscle fibre characteristics of leg extensor muscles. Acta Physiol. Scand. 125, 587-600. doi: 10.1111/j.1748-1716.1985.tb07760.x

Helms, E. R., Byrnes, R. K., Cooke, D. M., Haischer, M. H., Carzoli, J. P., Johnson, T. K. et al. (2018). RPE vs. percentage 1RM loading in periodized programs matched for sets and repetitions. Front. Physiol. 9:247. doi: 10.3389/fphys.2018.00247

Helms, E. R., Cronin, J., Storey, A., and Zourdos, M. C. (2016). Application of the repetitions in reserve-based rating of perceived exertion scale for resistance training. Strength Cond. J. 38:42. doi: 10.1519/SSC.0000000000000218

Higgins, J. P. T., Thompson, S. G., Deeks, J. J., and Altman, D. G. (2003). Measuring inconsistency in meta-analyses. BMJ 327, 557-560. doi: $10.1136 /$ bmj. 327.7414 .557

Hoffman, J. R., Ratamess, N. A., Faigenbaum, A. D., Mangine, G. T., and Kang, J. (2007). Effects of maximal squat exercise testing on vertical jump performance in American college football players. J. Sports Sci. Med. 6:149. Available online at: https://www.jssm.org/jssm-06-149.xml\%3EFulltext

Izquierdo, M., González-Badillo, J. J., Häkkinen, K., Ibáñez, J., Kraemer, W. J., Altadill, A., et al. (2006). Effect of loading on unintentional lifting velocity declines during single sets of repetitions to failure during upper and lower extremity muscle actions. Int. J. Sports Med. 27, 718-724. doi: 10.1055/s-2005-872825

Jandačka, D., and Beremlijski, P. (2011). Determination of strength exercise intensities based on the load-power-velocity relationship. J. Hum. Kinet. 28, 33-44. doi: 10.2478/v10078-011-0020-2

Jidovtseff, B., Quievre, J., Hanon, C., and Crielaard, J. M. (2009). Inertial muscular profiles allow a more accurate training loads definition. Sci. Sports 24, 91-96. doi: $10.1016 /$ j.scispo.2008.09.002

Julio, U. F., Panissa, V. L. G., and Franchini, E. (2012). Prediction of one repetition maximum from the maximum number of repetitions with submaximal loads in recreationally strength-trained men. Sci. Sports 27, e69e76. doi: 10.1016/j.scispo.2012.07.003

Keller, J. L., Housh, T. J., Smith, C. M., Hill, E. C., Schmidt, R. J., and Johnson, G. O. (2018). Sex-related differences in the accuracy of estimating target force using percentages of maximal voluntary isometric contractions vs. ratings of perceived exertion during isometric muscle actions. J Strength Cond. Res. 32, 3294-3300. doi: 10.1519/JSC.0000000000002210

Kelly, A. M., and Rubinstein, N. A. (1980). Why are fetal muscles slow? Nature 288, 266-269. doi: 10.1038/288266a0

Kimitake, S., George, K. B., Kevin, C., Caleb, B., Zhanxin, S., and Haff, G. G. (2015). Validity of wireless device measuring velocity of resistance exercises. J. Trainol. 4, 15-18. doi: 10.17338/trainology.4.1_15 
Kraemer, W. J., and Fleck, S. J. (2007). Optimizing Strength Training: Designing Nonlinear Periodization Workouts. Champaign, IL: Human Kinetics.

Lauersen, J. B., Bertelsen, D. M., and Andersen, L. B. (2014). The effectiveness of exercise interventions to prevent sports injuries: a systematic review and meta-analysis of randomised controlled trials. Br. J. Sports Med. 48, 871-877. doi: 10.1136/bjsports-2013-092538

Lehnhard, R. A., Lehnhard, H. R., Young, R., and Butterfield, S. A. (1996). Monitoring injuries on a college soccer team: the effect of strength training. J. Strength Cond. Res. 10, 115-119. doi: 10.1519/00124278-199605000-00011

Luebbers, P. E., Fry, A. C., Kriley, L. M., and Butler, M. S. (2014). The effects of a 7-week practical blood flow restriction program on well-trained collegiate athletes. J. Strength Cond. Res. 28, 2270-2280. doi: 10.1519/JSC.0000000000000385

Maher, C. G., Sherrington, C., Herbert, R. D., Moseley, A. M., and Elkins, M. (2003). Reliability of the PEDro scale for rating quality of randomized controlled trials. Phys. Ther. 83, 713-721. doi: 10.1093/ptj/83.8.713

Mann, J. B. (2011). A Programming Comparison: The APRE vs. Linear Periodization in Short Term Periods. Columbia, MO: University of Missouri.

Mann, J. B., Thyfault, J. P., Ivey, P. A., and Sayers, S. P. (2010). The effect of autoregulatory progressive resistance exercise vs. linear periodization on strength improvement in college athletes. J. Strength Cond. Res. 24, 1718-1723. doi: 10.1519/JSC.0b013e3181def4a6

Materko, W., Duarte, M., Santos, E. L., and Junior, H. S. (2010). Comparison between two strength training systems on the maximum muscular strength performance/Comparacao entre dois sistemas de treino de forca no desenvolvimento da forca muscular maxima. Motricidade 6, 5-14. doi: 10.6063/motricidade.6(2).147

McLeod, T. C., Armstrong T Fau - Miller, M., Miller M Fau - Sauers, J. L., and Sauers, J. L. (2009). Balance improvements in female high school basketball players after a 6-week neuromuscular-training program. J. Sport Rehabil. 18, 465-481. doi: 10.1123/jsr.18.4.465

Naclerio, F., Rodríguez-Romo, G., Barriopedro-Moro, M. I., Jiménez, A., Alvar, B. A., and Triplett, N. T. (2011). Control of resistance training intensity by the omni perceived exertion scale. J. Strength Cond. Res. 25, 1879-1888. doi: 10.1519/JSC.0b013e3181e501e9

Niewiadomski, W., Laskowska, D., Gasiorowska, A., Cybulski, G., Strasz, A., and Langfort, J. (2008). Determination and prediction of one repetition maximum (1RM): safety considerations. J. Hum. Kinet. 19, 109-120. doi: 10.2478/v10078-008-0008-8

Orange, S. T., Metcalfe, J. W., Liefeith, A., Marshall, P., Madden, L. A., Fewster, C. R., et al. (2019a). Validity and reliability of a wearable inertial sensor to measure velocity and power in the back squat and bench press. J. Strength Cond. Res. 33, 2398-2408. doi: 10.1519/JSC.0000000000002574

Orange, S. T., Metcalfe, J. W., Robinson, A., Applegarth, M. J., and Liefeith, A. (2019b). Effects of in-season velocity- versus percentage-based training in academy rugby league players. Int. J. Sports Physiol. Perform. 15, 554-561. doi: 10.1123/ijspp.2019-0058

Patrick, T. J., Bellar, D., Judge, L. W., and Craig, B. (2011). Correlation of height and preseason bench press $1 \mathrm{rm}$ to shot put and weight throw performance during the competitive season. J. Strength Cond. Res. 25, S97-S98. doi: 10.1097/01.JSC.0000395733.52859.53

Patroklos, A. K., James, F., Panagiotis, K., Paulo, G., and James, S. (2018). Reduced volume "daily max" training compared to higher volume periodized training in powerlifters preparing for competition-a pilot study. Sports 6:86. doi: $10.3390 /$ sports 6030086

Patterson, P. D., Weaver, M. D., Guyette, F. X., and Christian, M. (2020). Should public safety shift workers be allowed to nap while on duty? Am. J. Ind. Med. 63, 843-850. doi: 10.1002/ajim.23164

PEDro Scale Physiotherapy Evidence Database (2010). PEDro Scale. Available online at: http://www.pedro.org.au/english/downloads/pedro-scale/ (accessed September 29, 2020).

Peta, H. (2019). The Influence of Velocity-Based Resistance Training on Strength and Power Development. Hamilton: University of Waikato.

Poliquin, C. (1988). FOOTBALL: five steps to increasing the effectiveness of your strength training program. Strength Cond. J. 10, 34-39.

Radin, E. L. (1986). Role of muscles in protecting athletes from injury. Acta Med. Scand. 220, 143-147. doi: 10.1111/j.0954-6820.1986.tb0 8943.x
Rhea, M. R., Ball, S. D., Phillips, W. T., and Burkett, L. N. (2002). A comparison of linear and daily undulating periodized programs with equated volume and intensity for local muscular endurance. J. Strength Cond. Res. 17, 82-87. doi: 10.1519/00124278-200302000-00014

Robertson, R. J., Goss, F. L., Rutkowski, J., Lenz, B., Dixon, C., Timmer, J., et al. (2003). Concurrent validation of the OMNI perceived exertion scale for resistance exercise. Med. Sci. Sports Exerc. 35, 333-341. doi: 10.1249/01.MSS.0000048831.15016.2A

Ronnestad, B. R., Kvamme, N. H., Sunde, A., and Raastad, T. (2008). Shortterm effects of strength and plyometric training on sprint and jump performance in professional soccer players. J. Strength Cond. Res. 22, 773-780. doi: 10.1519/JSC.0b013e31816a5e86

Rubinstein, N. A., and Kelly, A. M. (1978). Myogenic and neurogenic contributions to the development of fast and slow twitch muscles in rat. Dev. Biol. 62, 473-485. doi: 10.1016/0012-1606(78)90229-4

Sander, A., Keiner, M., Wirth, K., and Schmidtbleicher, D. (2013). Influence of a 2year strength training programme on power performance in elite youth soccer players. Eur. J. Sport Sci. 13, 445-451. doi: 10.1080/17461391.2012.742572

Scott, T. J., Black, C. R., Quinn, J., and Coutts, A. J. (2013). Validity and reliability of the session-rpe method for quantifying training in australian football: a comparison of the CR10 and CR100 scales. J. Strength Cond. Res. 27, 270-276. doi: 10.1519/JSC.0b013e3182541d2e

Shalfawi, S. A. I., and Kjellstadli, B. (2018). "The effect of hypertrophy strength training using traditional set vs. cluster set on maximum strength and sprinting speed," in Proceedings of the 20th International Conference on Sport Science and Sports Engineering (Stavanger: Department of Education and Sports Science, University of Stavanger).

Shariat, A., Cleland, J. A., Danaee, M., Alizadeh, R., Sangelaji, B., Kargarfard, M., et al. (2018). Borg CR-10 scale as a new approach to monitoring office exercise training. Work 60, 549-554. doi: 10.3233/WOR-182762

Singh, G. (2016). The Influence of Velocity Based Resistance Training on Neuromuscular Strength and Power Adaptations in Semi-Professional Rugby Union and Professional Rugby League Players. Auckland: Auckland University of Technology.

Spiteri, T., Cochrane, J. L., Hart, N. H., Haff, G. G., and Nimphius, S. (2013). Effect of strength on plant foot kinetics and kinematics during a change of direction task. Eur. J. Sport Sci. 13, 646-652. doi: 10.1080/17461391.2013.774053

Spiteri, T., Newton, R. U., Binetti, M., Hart, N. H., Sheppard, J. M., and Nimphius, S. (2015). Mechanical determinants of faster change of direction and agility performance in female basketball athletes. J. Strength Cond. Res. 29, 2205-2214. doi: 10.1519/JSC.0000000000000876

Steele, J., Endres, A., Fisher, J., Gentil, P., and Giessing, J. (2017). Ability to predict repetitions to momentary failure is not perfectly accurate, though improves with resistance training experience. PeerJ. 5, e4105-e4105. doi: $10.7717 /$ peerj.4105

Stone, M. H. (1988). Implications for connective tissue and bone alterations resulting from resistance exercise training. Med. Sci. Sports Exerc. 20, S162S168. doi: 10.1249/00005768-198810001-00013

Styles, W. J., Matthews, M. J., and Comfort, P. (2016). Effects of strength training on squat and sprint performance in soccer players. J. Strength Cond. Res. 30, 1534-1539. doi: 10.1519/JSC.0000000000001243

Suchomel, T. J., Nimphius, S., and Stone, M. H. (2016). The importance of muscular strength in athletic performance. Sports Med. 46, 1419-1449. doi: $10.1007 / s 40279-016-0486-0$

Suzuki, K., Tominaga, T., Ruhee, R. T., and Ma, S. (2020). Characterization and modulation of systemic inflammatory response to exhaustive exercise in relation to oxidative stress. Antioxidants 9:401. doi: 10.3390/antiox90 50401

Tesch, P. A., Ekberg, A., Lindquist, D. M., and Trieschmann, J. T. (2004). Muscle hypertrophy following 5-week resistance training using a nongravity-dependent exercise system. Acta Physiol. Scand. 180, 89-98. doi: 10.1046/j.0001-6772.2003.01225.x

Van Cutsem, M., Duchateau, J., and Hainaut, K. (1998). Changes in single motor unit behaviour contribute to the increase in contraction speed after dynamic training in humans. J. Physiol. 513, 295-305. doi: 10.1111/j.1469-7793.1998.295by.x

Warren, G. L., Park, N. D., Maresca, R. D., McKibans, K. I., and Millard-Stafford, M. L. (2009). Effect of caffeine ingestion 
on muscular strength and endurance: a meta-analysis. Med. Sci. Sports Exerc. 42, 1375-1387. doi: 10.1249/MSS.0b013e3181c abbd8

Weber, C. J. (2015). Effects of Autoregulatory Progressive Resistance Exercise Periodization versus Linear Periodization on Muscular Strength and Anaerobic Power in Collegiate Wrestlers. Whitewater, WI: University of Wisconsin.

Wentworth, M. C., and Abadie, B. R. (1998). Prediction of 1-RM strength from a 5-10 RM submaximal strength test in college-age females. Med. Sci. Sports Exerc. 30:214. doi: 10.1097/00005768-19980500101221

Yan, B., Lai, X., Yi, L., Wang, Y., and Hu, Y. (2016). Effects of five-week resistance training in hypoxia on hormones and muscle strength. J. Strength Cond. Res. 30, 184-193. doi: 10.1519/JSC.0000000000 001056
Zhihui, W. (2020). The Effect of Velocity-Based Strength Training on the Lower Limbs Power-Related Athletic Abilities of College Basketball Athletes by Back Squat. Wuhan: Wuhan Sports University.

Conflict of Interest: The authors declare that the research was conducted in the absence of any commercial or financial relationships that could be construed as a potential conflict of interest.

Copyright (C) 2021 Zhang, Li, Bi, Luo, Cao and Zhang. This is an open-access article distributed under the terms of the Creative Commons Attribution License (CC BY). The use, distribution or reproduction in other forums is permitted, provided the original author(s) and the copyright owner(s) are credited and that the original publication in this journal is cited, in accordance with accepted academic practice. No use, distribution or reproduction is permitted which does not comply with these terms. 